Arq. Bras. Med. Vet. Zootec., v.69, n.3, p.711-717, 2017

\title{
Metionina+cistina digestível para juvenis de tambaqui
}

\author{
[Digestible methionine+cystine for tambaqui juveniles] \\ L.P. Gonçalves Júnior ${ }^{1}$, J.G.S. Sousa ${ }^{2}$, P.D.C. Selvatici ${ }^{1}$, L.F. Mendes $^{3}$, \\ J.G. Vargas Júnior ${ }^{1}$, P.P. Mendonça ${ }^{3}$ \\ ${ }^{1}$ Universidade Federal do Espírito Santo - Alegre, Espírito Santo, Brasil \\ ${ }^{2}$ Universidade Estadual do Norte Fluminense Darcy Ribeiro - Campos dos Goytacazes, RJ \\ ${ }^{3}$ Instituto Federal de Educação, Ciências e Tecnologia do Espírito Santo - Campus de Alegre - Alegre, ES
}

\section{RESUMO}

Avaliou-se o efeito dos níveis de metionina+cistina digestível para juvenis de tambaqui na fase inicial de desenvolvimento $(3,03 \pm 0,06 \mathrm{~g})$ durante 45 dias. Foram utilizados 160 juvenis de tambaqui distribuídos em DIC, com cinco tratamentos (níveis de metionina+cistina digestível $=0,66 ; 0,73 ; 0,80 ; 0,87 ; 0,94 \%$ ), quatro repetições e oito animais por unidade experimental. As dietas utilizadas foram isoproteicas (25\%) e isoenergéticas (3200 $\mathrm{kcal}^{\mathrm{kg}} \mathrm{kg}^{-1}$ ). Os resultados obtidos foram submetidos aos testes de homogeneidade, normalidade, à análise de variância e à análise de regressão. Os parâmetros físicos e químicos da água do sistema de recirculação ficaram dentro da faixa de tolerância para a espécie. Os níveis de metionina+cistina digestíveis avaliados não influenciaram $(\mathrm{P}>0,05)$ a sobrevivência, o índice hepatossomático, o índice de gordura visceral e o consumo de ração. Entretanto, ganho de peso e taxa de eficiência proteica apresentaram aumento linear $(\mathrm{P}<0,05)$ com aumento da metionina + cistina na ração. Verificou-se que os níveis de metionina + cistina para o tambaqui não foram completamente atendidos, sendo recomendada a realização de novos estudos.

Palavras-chave: aminoácido, Caracídeos, Colossoma macropomum, nutrição

\begin{abstract}
This study aimed to determine digestible methionine+cystine requirement of tambaqui juveniles in the early stage of development ( $3.03 \pm 0.06 \mathrm{~g}$ ) lasting 45 days. 160 tambaqui juveniles were distributed into DIC, with five treatments (methionine + cystine $=0.66 ; 0.73 ; 0.80 ; 0.87 ; 0.94 \%$ ), four replications and eight animals per experimental unit. The basal diets were isonitrogenous (25\% crude protein) and isocaloric (3200 $\left.\mathrm{kcal}^{\mathrm{kg}} \mathrm{g}^{-1}\right)$. The results were submitted to the homogeneity test, normality test, analysis of variance, and regression analysis. The physical and chemical parameters of water from the water recirculation system were within those recommended for the species. Digestible methionine+cystine levels did not influence $(P>0.05)$ the survival, hepatosomatic index, visceral fat index and feed intake. However, weight gain and protein efficiency ratio exhibit a linear increase $(P<0.05)$ with increase in methionine and cystine in the feed. Our results showed that the methionine + cystine levels for tambaqui were not fully met, and new studies are recommended.
\end{abstract}

Keywords: amino acids, Caracídeos, Colossoma macropomum, nutrition

\section{INTRODUÇÃO}

O padrão de aminoácidos corporais pode ser empregado para determinar as exigências dos peixes por aminoácidos (Abimorad e Castellani, 2011). Tal método é embasado no princípio de

Recebido em 1 de julho de 2016

Aceito em 6 de julho de 2016

E-mail: juniorvezula@hotmail.com que a necessidade em aminoácidos possui valor igual ou superior ao perfil de aminoácidos da carcaça. Entretanto, o estado fisiológico dos animais utilizados como referência tem resultado em divergências quanto ao uso desse método (Bomfim et al., 2008). E, ainda, o perfil aminoacídico corporal não é o indicativo do 


\section{Gonçalves Júnior et al.}

padrão ideal proteico de uma ração, sendo indicado pelos pesquisadores o estudo individual de cada aminoácido pelo método dose-resposta (Rampe et al., 2014).

Observa-se, na literatura, escassez de trabalhos com o objetivo de determinar as exigências de aminoácidos para as espécies nativas, principalmente para aquelas que possuem alta capacidade produtiva, como o tambaqui (Colossoma macropomun). O tambaqui vem sendo a principal espécie nativa cultivada, representando $29,3 \%$ do total nacional (Produção..., 2014), necessitando, assim, de mais trabalhos que potencializem sua produção, por exemplo os que definem níveis nutricionais de aminoácidos, como os sulfurados.

Os aminoácidos sulfurados são os primeiros aminoácidos limitantes em dietas à base de ingrediente de origem vegetal, como o milho e o farelo de soja (Nutrient..., 2011). A metionina é aminoácido essencial para o crescimento animal, no entanto pode ser metabolizada e convertida à cistina (Wilson, 2003). Devido às dificuldades de monitorar e quantificar a conversão de metionina a cistina, pesquisadores vêm estudando a exigência desses aminoácidos em conjunto, em que normalmente é expressa a necessidade de metionina+cistina (Michelato et al., 2013).

A metionina atua como doador do grupo metila, precursora de vários substratos incluindo ácidos nucleicos, proteínas, fosfolipídios, aminas carnitina, cisteína e colina (Wilson, 2003). Também exerce funções no sistema imune (Elmada et al., 2016) e na atividade antioxidante (MA et al., 2013). Estudos vêm demonstrando que a suplementação de metionina+cistina pode melhorar o desempenho, a conversão alimentar e a taxa de eficiência proteica dos peixes (Mai et al., 2006; Bomfim et al., 2008). Assim, objetivou-se determinar o nível ideal de metionina+cistina digestível para juvenis de tambaqui.

\section{MATERIAL E MÉTODOS}

O experimento foi realizado no Instituto Federal de Educação, Ciências e Tecnologia do Espírito Santo (Ifes), Campus de Alegre, Laboratório de Nutrição e Produção de Espécies Ornamentais (LNPEO). Foi utilizado o delineamento inteiramente ao acaso (DIC), com cinco tratamentos e quatro repetições. Os tratamentos corresponderam aos níveis de metionina+cistina digestível $(0,66 ; 0,73 ; 0,80 ; 0,87 ; 0,94 \%)$.

Foram utilizados 160 juvenis de tambaqui $(3,03 \pm 0,06 \mathrm{~g})$, distribuídos em 20 unidades experimentais de volume útil de 40L (oito peixes por unidade) em sistema de recirculação de água. $\mathrm{O}$ tratamento de água era composto por filtro mecânico de náilon, filtragem biológica em quatro caixas de $200 \mathrm{~L}$ preenchidas com tela de malha de $1 \mathrm{~mm}$ para fixação das bactérias nitrificantes e aquecimento por aquecedores com termostato. Diariamente foi realizado o sifonamento para retirar o excesso de fezes com renovação de água de 10\%. A água de reposição foi proveniente do sistema de tratamento de água para abastecimento urbano, previamente declorada em reservatório de 5.000L.

As dietas experimentais isoproteicas $(25 \%$ de proteína bruta) e isocalóricas (3200kcal.kg) foram formuladas (Tab. 1) de acordo com recomendações de Vidal Jr. et al. (1998), as quais foram transformadas em digestíveis utilizando-se os coeficientes de digestibilidade dos ingredientes definidos por Furuya (2010). As dietas foram suplementadas com aminoácidos sintéticos em quantidades suficientes para se obterem os níveis desejados de lisina, metionina + cistina e treonina digestíveis. Os ingredientes foram homogeneizados, a eles foram adicionados $9 \%$ de água a $45^{\circ} \mathrm{C}$, foram peletizados em diâmetro de $3 \mathrm{~mm}$ e destinados à estufa de circulação forçada a $55^{\circ} \mathrm{C}$ por 24 horas. As rações foram fornecidas quatro vezes ao dia (7h30, 10h30, 13h30, 16h30), à vontade, até a saciedade aparente.

Foram avaliados parâmetros físico-químicos da água durante todo o período experimental, sempre após a última alimentação. Para medição da temperatura $\left({ }^{\circ} \mathrm{C}\right)$, realizada diariamente, utilizou-se termômetro de bulbo de mercúrio. Os demais parâmetros foram mensurados duas vezes na semana, sendo oxigênio dissolvido (mg.L) com oxímetro microprocessado modelo DO5519, pH da água com peagâmetro digital modelo PH-0016, condutividade elétrica $(\mu \mathrm{S})$ com condutivímetro digital modelo CD-850; amônia total por kit colorimétrico.

Ao final do $44^{\circ}$ dia, os animais foram mantidos em jejum por 16 horas e, após esse período, foi 
realizada a biometria final com paquímetro e balança analítica de precisão de 0,1mg. Assim, foram verificados os valores individuais de peso (g), comprimento total (cm), comprimento padrão $(\mathrm{cm})$, altura $(\mathrm{cm})$ e sobrevivência $(\mathrm{S})$. Três animais de cada unidade experimental foram anestesiados com eugenol $100 \mathrm{mg} / \mathrm{L}$ (Roubach et al., 2005) e eutanasiados por secção medular. Posteriormente foi mensurado o peso do fígado e da gordura visceral. Desse modo, foi possível estimar o índice hepatossomático (IHS) e o índice de gordura visceral (IGV). O desempenho produtivo foi avaliado pelo ganho de peso (GP), consumo de ração (CR), consumo de metionina+cistina (C) conversão alimentar aparente (CAA), taxa de eficiência proteica
(TEP), taxa de eficiência da metionina + cistina (TEM) e pela taxa de crescimento específico (TCE).

$\mathrm{CAA}=($ peso final $(\mathrm{g})-$ peso inicial $(\mathrm{g})) /$ alimento consumido no período $(\mathrm{g})$;

$\mathrm{TEP}=[($ peso final $(\mathrm{g})-$ peso inicial $(\mathrm{g})] /$ total de proteína ingerida $(\mathrm{g})$;

$\mathrm{TEM}=[($ peso final $(\mathrm{g})-$ peso inicial $(\mathrm{g})] /$ total de metionina+cistina ingerido $(\mathrm{g})$;

$\mathrm{TCE}=\left[(\log\right.$ peso final $-\log$ peso inicial $) / \mathrm{n}^{\mathrm{o}} \mathrm{de}$ dias experimentais) ] x 100;

$\mathrm{IHS}=[$ (peso do fígado fresco/peso corporal $)] \mathrm{x}$ 100 ;

$\mathrm{IGV}=[($ peso da gordura visceral/peso corporal $)]$ $\mathrm{x} 100$.

Tabela 1. Composição calculada das dietas experimentais com base na matéria natural para os diferentes níveis de metionina+cistina digestível

\begin{tabular}{|c|c|c|c|c|c|}
\hline \multirow[b]{2}{*}{ Ingredientes (\%) } & \multicolumn{5}{|c|}{ Níveis de metionina+cistina digestível (\%) } \\
\hline & 0,66 & 0,73 & 0,8 & 0,87 & 0,94 \\
\hline Milho grão & 54,94 & 54,77 & 54,62 & 54,47 & 54.30 \\
\hline Glúten de milho $60 \%$ & 4,02 & 3,81 & 3,59 & 3,38 & 3,17 \\
\hline Farinha de peixe $55 \%$ & 8,00 & 8,03 & 8,05 & 8,08 & 8,11 \\
\hline Farelo de Soja 45\% & 30,53 & 30,82 & 31,10 & 31,38 & 31,67 \\
\hline Sup. vitamínico ${ }^{1}$ & 0,10 & 0,10 & 0,10 & 0,10 & 0,10 \\
\hline Vitamina $\mathrm{C}$ & 0,10 & 0,10 & 0,10 & 0,10 & 0,10 \\
\hline Sup. mineral ${ }^{2}$ & 0,05 & 0,05 & 0,05 & 0,05 & 0,05 \\
\hline Óleo de soja & 2,0 & 2,0 & 2,0 & 2,0 & 2,0 \\
\hline L-lisina $\mathrm{HCl} 78,4 \%$ & 0,16 & 0,15 & 0,14 & 0,13 & 0,12 \\
\hline DL-metionina $99 \%$ & 0,02 & 0,09 & 0,17 & 0,24 & 0,31 \\
\hline L-treonina 99\% & 0,07 & 0,07 & 0,07 & 0,06 & 0,06 \\
\hline BHT & 0,01 & 0,01 & 0,01 & 0,01 & 0,01 \\
\hline \multicolumn{6}{|l|}{ Composição (\%) } \\
\hline Proteína bruta & 25,00 & 25,00 & 25,00 & 25,00 & 25,00 \\
\hline Energia digestível kcal.kg & 3200,0 & 3200,0 & 3200,0 & 3200,0 & 3200,0 \\
\hline Fibra bruta ${ }^{3}$ & 2,61 & 2,62 & 2,63 & 2,64 & 2,65 \\
\hline Cálcio $^{3}$ & 0,57 & 0,57 & 0,58 & 0,58 & 0,58 \\
\hline Fósforo disponível ${ }^{3}$ & 0,33 & 0,33 & 0,33 & 0,33 & 0,33 \\
\hline Lisina digestível $^{3}$ & 1,45 & 1,45 & 1,45 & 1,45 & 1,45 \\
\hline Treonina digestível $^{3}$ & 0,85 & 0,85 & 0,85 & 0,85 & 0,85 \\
\hline Metionina + cistina digestível $^{3}$ & 0,66 & 0,73 & 0,8 & 0,87 & 0,94 \\
\hline Metionina + cistina total & 0,89 & 0,96 & 1,03 & 1,10 & 1,17 \\
\hline Metionina total & 0,49 & 0,56 & 0,63 & 0,70 & 0,77 \\
\hline Relação cistina:metionina & 81,63 & 71,42 & 63,49 & 57,14 & 51,94 \\
\hline
\end{tabular}

${ }^{1}$ Composição por quilograma do produto: vit. A, 8.000.000UI; vit. D3, 2.500.000UI; vit. E, 8.000mg; vit. K3, $1.500 \mathrm{mg}$; vit. B1, $1.000 \mathrm{mg}$; vit. B2, 4.000mg; vit. B6, $1.000 \mathrm{mg}$; vit. B12, 12.000mg; niacina, 20g; pantotenato de cálcio, 8.000mg; ácido fólico, 300mg; biotina, 20mg. ${ }^{2} \mathrm{Composição} \mathrm{por} \mathrm{quilograma} \mathrm{do} \mathrm{produto:} \mathrm{Fe}, 96 \mathrm{~g}$; $\mathrm{Cu}, 20 \mathrm{~g}$; Mn, 155g; Zn, 110g; I,1.400mg; Se, 360mg. ${ }^{3}$ Valores calculados com base no determinado para a tilápia-do-nilo (Furuya, 2010). 


\section{Gonçalves Júnior et al.}

Os resultados obtidos foram submetidos à análise de homogeneidade e normalidade das variâncias. Posteriormente, foi realizada a análise de variância e, em seguida, a análise de regressão, por meio do programa estatístico Sisvar.

Os procedimentos experimentais foram aprovados pela Comissão de Ética no Uso de Animais da Universidade Federal do Espírito Santo, protocolo número 57/2015.

\section{RESULTADOS E DISCUSSÕES}

Os parâmetros físicos e químicos da água do sistema de recirculação ficaram dentro da faixa de tolerância para o tambaqui (oxigênio dissolvido: $\quad 4,4 \pm 1,0 \mathrm{mg} . \mathrm{L}_{-}{ }^{1} ; \quad \mathrm{pH}: 6,5 \pm 0,5$; temperatura: $28,9 \pm 0,7^{\circ} \mathrm{C}$; amônia total $1,94 \pm 1,31 \mathrm{mg}^{\mathrm{L}}-^{-1} ; \quad$ condutividade elétrica $119,2 \pm 14,1 \mu \mathrm{Sm})$, conforme o recomendado por Oliveira et al. (2007). O nível de amônia total foi relativamente elevado, entretanto essa não interferiu no crescimento e na sobrevivência dos animais em razão da baixa toxidade em água com pH ligeiramente ácido.

$\mathrm{O}$ peso final, o comprimento total, o comprimento padrão, a taxa de crescimento específico e o consumo de metionina+cistina apresentaram efeito linear em razão do aumento de 0,66 para $0,94 \%$ no nível de metionina+cistina digestível (Tab. 2). No entanto, não foi observado efeito para as variáveis sobrevivência, altura, índice hepatossomático, índice de gordura visceral e consumo de ração. $\mathrm{O}$ resultado mais satisfatório para o desempenho zootécnico foi obtido para o maior nível de metionina + cistina digestível avaliado $(0,94 \%)$. Tais resultados indicam que o requerimento em aminoácidos sulfurados para o tambaqui não foi completamente atendido.

O valor obtido no presente experimento é próximo a $1,00 \%$ verificado para o ótimo desempenho de juvenis de tilápia (Oreochromis niloticus) com peso inicial de 2,61 $\pm 0,14 \mathrm{~g}$ (Furuya et al., 2004). Porém, é superior a 0,86\% estimado em outro estudo com juvenis de tilápia (O. niloticus) na mesma fase de desenvolvimento (peso inicial $=0,86 \pm 0,02 \mathrm{~g}$ ) (Bomfim et al., 2008). Para juvenis de corvina (Pseudosciaena crocea) com peso inicial de $1.23 \pm 0.02 \mathrm{~g}$, foi recomendado nível mínimo de $1,68 \%$ de metionina + cistina na dieta (Mai et al., 2006). De maneira geral, o requerimento em metionina+cistina total na dieta pode variar entre 0,82 e 2,80\% (Nutrient..., 2011). Essa variação nos resultados pode ser atribuída às diferenças nas dietas basais, ao modelo estatístico empregado na interpretação dos resultados, às condições das instalações experimentais, à fase de desenvolvimento e à espécie.

Tabela 2. Valores médias \pm desvio padrão para as variáveis sobrevivência $(\mathrm{S})$, peso $(\mathrm{P})$, comprimento total (CT), comprimento padrão (CP), altura (A), índice hepatossomático (IHS), índice de gordura visceral (ICV), taxa de crescimento específica (TCE), consumo de ração (CR), consumo de metionina+cistina (C) para os juvenis de tambaqui alimentados com diferentes níveis de metionina+cistina digestível

\begin{tabular}{ccccccc}
\hline \multirow{2}{*}{ Variáveis } & \multicolumn{7}{c}{ Níveis de metionina+cistina digestível } \\
\cline { 2 - 6 } & 0,66 & 0,73 & 0,80 & 0,87 & 0,94 & $\mathrm{CV}(\%)$ \\
\hline $\mathrm{S}(\%)$ & $100,00 \pm 0,0$ & $100,00 \pm 0,0$ & $100,00 \pm 0,0$ & $100,00 \pm 0,0$ & $100,00 \pm 0,0$ & - \\
$\mathrm{P}^{* 1}(\mathrm{~g})$ & $49,40 \pm 2,2$ & $51,94 \pm 2,0$ & $50,71 \pm 1,6$ & $54,11 \pm 3,6$ & $54,59 \pm 1,0$ & 5,64 \\
$\mathrm{CT}^{* 2}(\mathrm{~cm})$ & $14,01 \pm 0,2$ & $14,31 \pm 0,2$ & $14,25 \pm 0,2$ & $14,57 \pm 0,5$ & $14,49 \pm 0,6$ & 3,11 \\
$\mathrm{CP}^{* 3}(\mathrm{~cm})$ & $10,75 \pm 0,1$ & $10,82 \pm 0,2$ & $10,81 \pm 0,2$ & $11,14 \pm 0,3$ & $11,10 \pm 0,1$ & 2,41 \\
$\mathrm{~A}^{\mathrm{ns}}(\mathrm{cm})$ & $5,82 \pm 0,1$ & $5,86 \pm 0,1$ & $5,81 \pm 0,1$ & $5,88 \pm 0,1$ & $5,90 \pm 0,0$ & 2,03 \\
$\mathrm{IHS}^{\text {ns }}$ & $2,11 \pm 0,4$ & $2,27 \pm 0,5$ & $1,97 \pm 0,1$ & $2,20 \pm 0,2$ & $2,25 \pm 0,3$ & 17,86 \\
$\mathrm{IGV}^{\mathrm{ns}}$ & $1,01 \pm 0,2$ & $1,00 \pm 0,3$ & $1,26 \pm 0,2$ & $1,08 \pm 0,1$ & $1,07 \pm 0,3$ & 23,35 \\
$\mathrm{TCE}^{* 4}(\%)$ & $4,66 \pm 0,0$ & $4,70 \pm 0,0$ & $4,68 \pm 0,0$ & $4,81 \pm 0,1$ & $4,81 \pm 0,0$ & 1,95 \\
$\mathrm{CR}^{\text {ns }}(\mathrm{g})$ & $55,64 \pm 5,9$ & $54,39 \pm 3,5$ & $52,97 \pm 0,2$ & $56,07 \pm 0,1,4$ & $51,47 \pm 0,9$ & 5,03 \\
$\mathrm{C}^{* 5}\left(\mathrm{mg}^{\mathrm{dia}}{ }^{-1}\right)$ & $11,00 \pm 0,6$ & $11,39 \pm 0,7$ & $12,13 \pm 0,05$ & $13,61 \pm 0,4$ & $13,40 \pm 0,2$ & 9,48 \\
\hline $\mathrm{A}^{2}$
\end{tabular}

Análise de variância $={ }^{\text {ns }}$ não significativo; *probabilidade $(\mathrm{P}<0,05)$. ${ }^{1}$ Efeito linear $(\mathrm{P}=0,018 ; \hat{\mathrm{Y}}=17,919 \mathrm{x}+37,821$ : $\left.\mathrm{R}^{2}=0.808\right) .{ }^{2}$ Efeito linear $\left(\mathrm{P}=0,024 ; \hat{\mathrm{Y}}=1,75 \mathrm{x}+12,93 ; \mathrm{R}^{2}=0,776\right) .{ }^{3}$ Efeito linear $(\mathrm{P}=0,023 ; \hat{\mathrm{Y}}=1,4298 \mathrm{x}+$ 9,$\left.7842 ; \mathrm{R}^{2}=0,778\right) .{ }^{4}$ Efeito linear $\left(\mathrm{P}=0,021 ; \hat{\mathrm{Y}}=0,595 \mathrm{x}+4,2598: \mathrm{R}^{2}=0,793\right) .{ }^{5}$ Efeito linear $(\mathrm{P}=0,042 ; \hat{\mathrm{Y}}=$ $\left.10,018 \mathrm{x}+4,2969 ; \mathrm{R}^{2}=0,899\right)$. 
Assim como o verificado para o tambaqui ( $C$. macropomum) no presente experimento, $\mathrm{o}$ aumento dos níveis de metionina + cistina $(0,61$ a 1,64\%) não influenciou o índice hepatossomático e o índice de gordura visceral para o bagre-amarelo (Pelteobagrus fulvidraco) (Elmada et al., 2016). Esses resultados indicam que não ocorreu sobrecarga de utilização do fígado e alterações nas reservas lipídicas na cavidade visceral. Por outro lado, o nível de metionina pode influenciar o metabolismo de aminoácidos no fígado e as reservas lipídicas, sendo as alterações dependentes da natureza do desbalanceamento, excesso ou deficiência (Skiba-Cassy et al., 2016).

A redução do desempenho não foi determinada pela ingestão de alimento, uma vez que o consumo de ração não foi influenciado $(\mathrm{P}>0,05)$ pelo aumento dos níveis de metionina+cistina digestível de 0,66 para 0,94\%. Esse comportamento para o consumo de ração pode ser atribuído à não ativação do centro de regulação do consumo observado por outros autores em peixes alimentados com dietas contendo perfil de aminoácido desequilibrado (Mai et al., 2006; Bae et al., 2011). Dessa forma, os resultados do presente estudo para consumo de ração e crescimento indicam a necessidade da realização de novos estudos para que o nível de metionina+cistina digestível seja estabelecido para juvenis de tambaqui (C. macropomum).

A conversão alimentar aparente se reduziu em razão do aumento dos níveis de metionina+cistina digestível na ração (Fig. 1), mostrando efeito positivo da suplementação de metionina. Os níveis de metionina+cistina também melhoraram a conversão alimentar da corvina (P. crocea) (Mai et al., 2006), da tilápia (O. niloticus) (He et al., 2016) e do linguado (Psetta maxima) (Klatt et al., 2016). A redução na conversão alimentar aparente pode ser atribuída ao melhor balanceamento de aminoácidos à medida que se aumentou a metionina+cistina na dieta (Yamamoto et al., 2012), minimizando, assim, os efeitos negativos das relações de antagonismo (Skiba-Cassy et al., 2016).

O ganho de peso aumentou até o nível de 0,94\% de metionina+cistina digestível (Fig. 1), correspondente a $3,76 \%$ da proteína bruta em aminoácidos sulfurados digestíveis. Essa relação dos aminoácidos sulfurados com a proteína bruta foi superior aos $2,80 \%$ obtidos para o ótimo ganho de peso da tilápia (O. niloticus) (Nguyen e Davis, 2009) e aos 2,30\% obtidos para trutaarco-íris (Oncorhynchus mykiss) (Kim et al., 1992). Apesar das particularidades das dietas e das condições experimentais, Walter et al., (1995) também obsevaram maior relação entre os aminoácidos sulfurados e a proteína bruta para o tambaqui (peso inicial de 153g) quando comparado com outras espécies $(3,90 \%)$.

O aumento do nível de metionina favoreceu a taxa de eficiência proteica (Fig. 1). Tal resultado pode ser atribuído à redução da relação cistina:metionina de 81,63 para $51,94 \%$ e ao aumento na relação metionina+cistina:lisina digestível de 45,51 para 64,12\%. Esses resultados estão de acordo com a relação observada por Klatt et al. (2016) para o linguado (P. máxima) e por Bomfim, et al. (2008) para a tilápia (O. niloticus). No entanto, para o tambaqui (C. macropomum) ainda não se encontra estabelecido o requerimento em lisina, o que, de certa forma, limita a aplicação do conceito de proteína ideal.

A redução da taxa de eficiência da metionina+cistina (Fig. 1) pode ser atribuída à preferência de absorção dos aminoácidos sintéticos quando comparados aos aminoácidos oriundos das fontes proteicas naturais (Ambardekar e Williams, 2009). Isso resulta em maior velocidade de absorção, elevando as concentrações plasmáticas desses aminoácidos, e em desequilíbrio no sítio de síntese proteica (Bae et al., 2011); consequentemente, há o aumento do catabolismo dos aminoácidos em excesso (Gaylord e Barrows, 2009).

Outro aspecto que vem sendo atribuído à redução da eficiência de utilização dos aminoácidos livres é o aumento da lixiviação desses na água (Bomfim et al., 2010). No entanto, apesar da utilização de dieta peletizada, que, por sua vez, apresenta maior perda de nutrientes para a água quando comparada com as rações extrusadas (Rodrigues e Fernades, 2006), no presente estudo esse não foi o fator determinante, uma vez que os animais consumiram todo alimento logo após o fornecimento. 


\section{Gonçalves Júnior et al.}

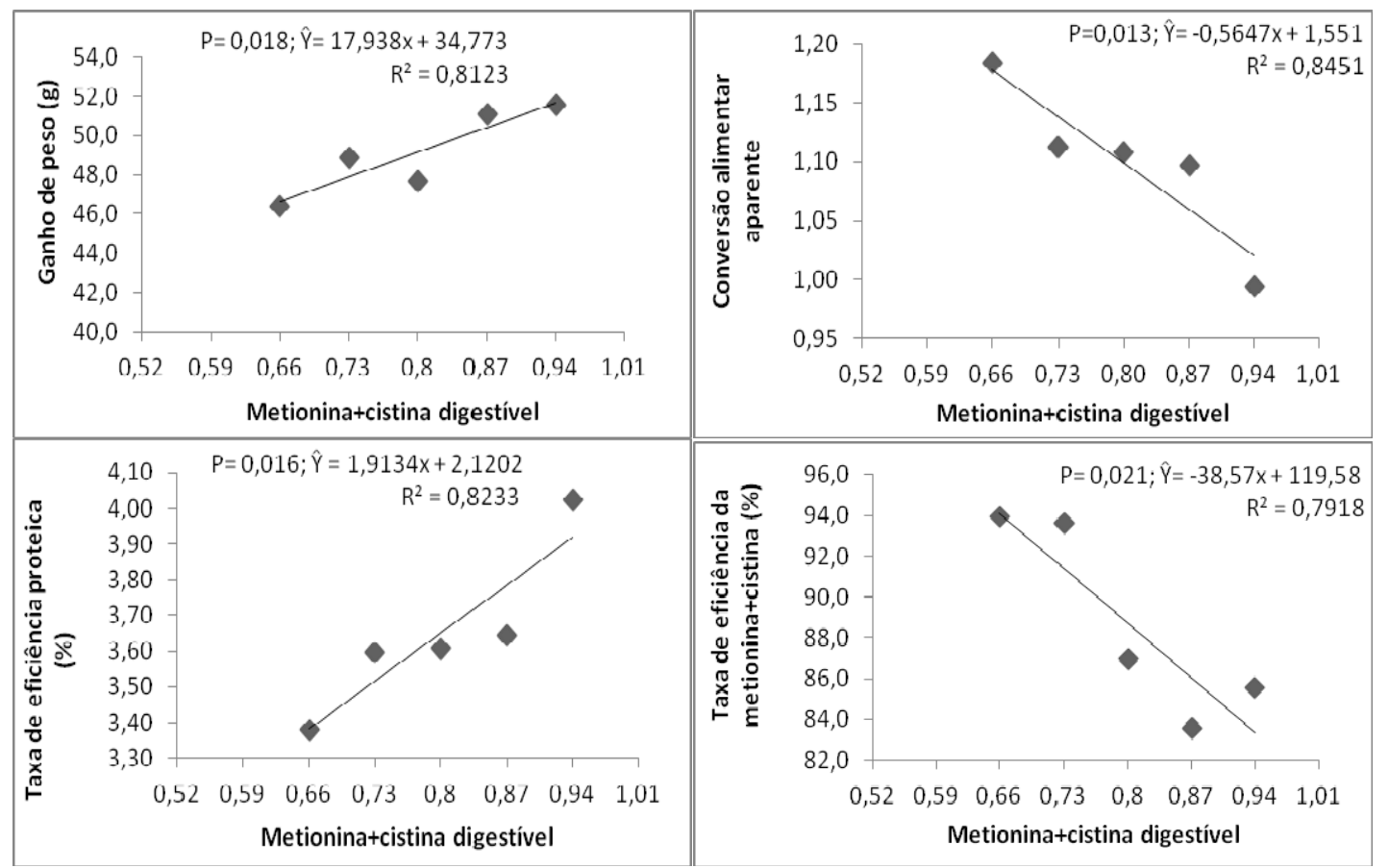

Figura 1. Efeito dos níveis de metionina+cistina digestível digestível no ganho de peso $(\mathrm{CV}=5,97 \%)$, na conversão alimentar aparente $(C V=6,49 \%)$, na taxa de eficiência proteíca $(C V=6,55 \%)$ e na taxa de eficiência da metionina+cistina digestível $(\mathrm{CV}=5,40 \%)$.

\section{CONCLUSÃO}

Recomenda-se que novas pesquisas sejam realizados para que a exigência de metionina + cistina digestível para o tambaqui nessa fase de estudo seja estabelecida.

\section{REFERÊNCIAS}

ABIMORAD, E.G.; CASTELLANI, D. Exigências nutricionais de aminoácidos para o lambari-do-raboamarelo baseadas na composição da carcaça e do músculo. Bol. Inst. Pesca, v.37, p.31-38, 2011.

AMBARDEKAR, R.C.; WILLIAMS, M.B. Absorption of amino acids from intact dietary proteins and purified amino acid supplements follows different time-courses in channel catfish (Ictalurus punctatus). Aquaculture, v.291, p.179-187, 2009.

BAE, J.Y.; OK, I.H.; LEE, S. et al. Re-evaluation of dietary methionine requirement by plasma methionine and ammonia concentrations in surgically modified rainbow trout, Oncorhynchus mykiss. Asian-Australas. J. Anim. Sci., v.24, p.974-981, 2011.

BOMFIM, M.A.D.; LANNA, E.A.T.; DONZELE, J.L. et al. Exigência de metionina mais cistina, com base no conceito de proteína ideal, em rações para alevinos de tilápia do nilo. Rev. Bras. Zootec., v.37, p.783-790, 2008.
BOMFIM, M.A.D.; LANNA, E.A.T.; DONZELE, J.L. et al. Níveis de lisina, com base no conceito de proteína ideal, em rações para alevinos de tilápia-donilo. Rev. Bras. Zootec., v.39, p.1-8, 2010.

ELMADA, C.Z.; HUANG, W.; JIN, M. et al. The effect of dietary methionine on growth, antioxidant capacity, innate immune response and disease resistance of juvenile yellow catfish (Pelteobagrus fulvidraco). Aquacult. Nutr., 2016. http://doi.wiley.com/10.1111/anu.12363, acesso: 22/02/2016.

FURUYA, W.M.; SILVA L.C.; NEVES, P.R. et al. Exigência de metionina + cistina para alevinos de tilápia do Nilo (Oreochromis niloticus). Cienc. Rural, v.34, p.1933-1937, 2004.

FURUYA, W.M. Tabelas brasileiras para a nutrição de tilápias. Toledo: GFM, 2010. 100p.

GAYLORD, T.G.; BARROWS, F.T. Multiple amino acid supplementations to reduce dietary protein in plant-based rainbow trout, Oncorhynchus mykiss, feeds. Aquaculture, v.287, p.180-184, 2009.

HE, J.Y.; TIAN, L.X.; LEMME, A. The effect of dietary methionine concentrations on growth performance of juvenile Nile tilapia (Oreochromis niloticus) fed diets with two different digestible energy levels. Aquac. 2016. http://doi.wiley.com/10.1111/anu.12362, acesso: 22/02/2016 
KIM, K.; KAYES, T.B.; AMUNDSON, C.H. Requirements for sulfur amino acids and utilization of D-methionine by the rainbow trout (Oncorhynchus mykiss). Aquaculture, v.101, p.95-103, 1992.

KLATT, S.F.; VON DANWITZ, A.; HASLER, M.; SUSENBETH, A. Determination of the lower and upper critical concentration of Methionine+Cystine in diets of juvenile turbot (Psetta maxima). Aquaculture, v.452, p.12-23, 2016.

MA, R.; HOU, H.; MAI, K. et al. Comparative study on the effects of L-methionine or 2-hydroxy-4(methylthio) butanoic acid as dietary methionine source on growth performance and anti-oxidative responses of turbot (Psetta maxima). Aquaculture, v.412-413, p.136-143, 2013.

MAI, K.; WAN, J.; AI, Q. et al. Dietary methionine requirement of large yellow croaker, Pseudosciaena crocea. Aquaculture, v.253, p.564-572, 2006.

MICHELATO, M.; FURUYA, W.M.; GRACIANO, T.S., Digestible methionine + cystine requirement for Nile tilapia from 550 to 700 g. Rev. Bras. Zootec., v.42, p.7-12, 2013.

NGUYEN, T.N.; DAVIS, D.A. Re-evaluation of total sulphur amino acid requeriment and determination of replacement value of cystine for methionine in semipurified diets of juvenile Nile tilapia, Oreochromis niloticus. Aquac. Nutr., v.15, p.247-253, 2009.

NUTRIENT requirements of fish and shrimp. Washington: National Academy of Sciences, 2011. 4p.

OLIVEIRA, R.P.C.; SILVA, P.C.; PADUA, D.M.C. et al. Efeitos da densidade de estocagem sobre a qualidade da água na criação do tambaqui, (Colossoma macropomum, cuvier, 1818) durante a segunda alevinagem, em tanques fertilizados, Cienc. Anim. Bras., v.8, p.705-711, 2007.

PROUÇÃO da pecuária municipal. [Rio de Janeiro]: IBGE, 2014. v.48, p.1-39.
RAMPE, M.C.C.; PACHECO, M.L.; VARGAS JÚNIOR, J.G.; et al. Adição de lisina digestível em rações experimentais para juvenis de tilápia-do-nilo. Arq. Bras. Med. Vet. Zootec., v.66, p.1557-1566, 2014.

RODRIGUES, A.; FERNANDES, J.B.K. Influência do processamento da dieta no desempenho produtivo do acará bandeira (Pterophyllum scalare). Acta Sci. Anim. Sci., v.28, p.113-119, 2006.

ROUBACH, R.; GOMES, L.C.; FONSECA, L.F.A.; VAL, A.L. Eugenol as an efficacious anaesthetic for tambaqui, Colossoma macropomum (Cuvier). Aquac. Res., v.36, p.1056-1061, 2005

SKIBA-CASSY, S.; GEURDEN, I.; PANSERAT, S.; SEILIEZ, I. Dietary methionine imbalance alters the transcriptional regulation of genes involved in glucose, lipid and amino acid metabolism in the liver of rainbow trout (Oncorhynchus mykiss). Aquaculture, v.454, p.56-65, 2016.

VIDAL JUNIOR, M.V.; DONZELE, J.L.; CAMARGO, A.C.S. et al. Níveis de proteína bruta para tambaqui (Colossoma macropomum), na fase de 30 a 250 gramas. 1. Desempenho dos tambaquis. Rev. Bras. Zootec., v.37, p.421-426, 1998.

WALTER, G.A.; JAVIER, Z.R.; MARIANO, R.A. Utilizacion de dietas practicas con diferentes niveles de aminoacidos azufrados totales para el crecimiento de gamitana (Colossoma macropopum), pisces Characidae. Folia Amaz., v.7, p.195-203, 1995.

WILSON, R.P. Amino acid requirements of finfish and crustaceans. In: D'MELIO, J.P.F. Amino acid in farm animal nutrition. Wallingford: $\mathrm{CAB}$ International, 2003. p.427-447.

YAMAMOTO, T.; MATSUNARI, H.; SUGITA, T. et al. Optimization of the supplemental essential amino acids to a fish meal-free diet based on fermented soybean meal for rainbow trout Oncorhynchus mykiss. Fish. Sci., v.78, p.359-366, 2012. 